\title{
Effect of vitamin D supplementation in severity and control of bronchial asthma in children
}

\author{
Agrahari A ${ }^{1}$, Dayal R. ${ }^{2}$, Gupta L.K. ${ }^{3}$, Bhatia R. ${ }^{4}$, Agarwal D. ${ }^{5}$, Kumar P. ${ }^{6}$, Pathak S. ${ }^{7}$, Kumar H. ${ }^{8}$ \\ ${ }^{1}$ Dr. Aneeta Agrahari ${ }^{1}$ Resident Doctor, ${ }^{2}$ Dr. Rajeshwar Dayal, Professor \& Head, ${ }^{3}$ Dr. L.K. Gupta, Senior Consultant, \\ District Women Hospital, Firozabad, ${ }^{4}$ Dr. Rakesh Bhatia, Professor, Department of Pediatrics, ${ }^{5}$ Dr. Dipti Agarwal, \\ Associate Professor, Department of Pediatrics, Ram Manohar Lohia Institute of Medical Sciences, Lucknow, ${ }^{6}$ Dr. Pankaj \\ Kumar, Associate Professor, ${ }^{7}$ Dr. Sunit Pathak, Associate Professor, Department of Paediatrics, F.H. Medical College, \\ Tundla, Firozabad, ${ }^{8}$ Dr. Harendra Kumar, Associate Professor, ${ }^{1,2,4,6,8}$ Authors are affiliated with Department of \\ Pathology, Sarojini Naidu Medical College, Agra, India.
}

Corresponding Author: Dr. L.K. Gupta, Senior Consultant, Pediatric, District Women Hospital, Firozabad (U.P.) India. E-mail: guptaneeta98@gmail.com

\begin{abstract}
Background: Asthma is characterized by chronic airway inflammation with history of recurrent respiratory symptoms such as wheeze, breathlessness, chest tightness, cough. Methodology: A prospective interventional study was conducted in Department of Paediatrics, S. N. Medical and Hospital, Agra. About 141 asthmatic children of age group $\leq 14$ years of either gender were selected. Baseline serum vitamin D level was done and children were divided in to two groups. Group A and Group B. Only moderate persistent severity children were included for further follow up study, based on VitaminD levels. Outcome was measured at $3 \& 6$ months, in all the groups in the form of Emergency-room visit per month, ACT score and Reliever-medication use per-week. Results: Among 141 patients, 49.7\% were 9-14years old, 53.9\% were males and 84.4\% suffering from moderate-persistent asthma. Mean Vitamin-D was significantly-lower in asthma patients with increasing severity. After starting standard-therapy and Vitamin-D supplementation, there was decrease in emergency-room visit and hospital-admission, decrease in requirement of reliever-medication for asthma and improvement in asthma control score. There was significant increase in ACT-score from 3 to 6 months follow-ups in all groups with highest score in subgroup-B2 patients. Conclusion: Vitamin-D supplementation was beneficial in asthma patients for relieving asthma exacerbation such as symptoms, reducing hospital-admission and emergency hospital visits.
\end{abstract}

Keywords: Asthmatic children, Vitamin D, Severity of asthma

\section{Introduction}

Asthma is one of the most common chronic respiratory diseases of childhood. Asthma patients are increasing globally secondary to both raising access to healthcare with more and more asthma diagnosis and to urbanization. Asthma in children is different compared to adult with multiple phenotypes and variable natural course. Most of time asthma is under-diagnosed and under-treated that result in poor quality of life in children and their parents.

Asthma in children had significant socio-economic impact on the families due to direct treatment cost and indirect cost due to wasted school days, hospitalization and lost days in parent's job [1].

Manuscript received: $14^{\text {th }}$ January 2019

Reviewed: $24^{\text {th }}$ January 2019

Author Corrected: $31^{\text {st }}$ January 2019

Accepted for Publication: 6 ${ }^{\text {th }}$ February 2019
Asthma is a chronic airway inflammation, defined by the history of recurrent respiratory symptoms such as wheeze, shortness of breath, chest tightness and cough that vary over time and in intensity, together with variable expiratory airflow limitation. According to Global Initiative for asthma, Asthma is classified as intermittent, mild persistent, moderate persistent and severe persistent [2]. Asthma is a problem worldwide with estimated 100 - 150 million people suffering from it, contributing to a large morbidity and economic burden. As per WHO estimated prevalence of asthma in India was 15-20 million [3].

Studies suggest relationship between vitamin D status and asthma-related symptoms presumably via immunomodulatory effects of vitamin D. Vitamin D is one of the major circulating hormone involved in bone 


\section{Original Research Article}

mineral homeostasis in the body. Newer studies had found new non skeletal roles of vitamin D in human health, including a role in preventing chronic diseases such as cardiovascular disease, diabetes and cancer [4]. In addition to these chronic diseases, vitamin $\mathrm{D}$ was a potent modulator of immune system and involve in regulation of cell proliferation and differentiation, might be linked to bronchial asthma [5]. Vitamin D had been associated with epidemiologic patterns of asthma epidemiology. It's deficiency is related with increased airway hyper-responsiveness, lower pulmonary function, worse asthma control and steroid resistance [6].

Vitamin D inhibits cytokine synthesis and release in bronchial smooth muscle cells causing decrease in lung inflammation, inhibition of bronchial smooth muscle cells proliferation and remodeling by inhibition of MMP-9, MMP-33 and PDGF. It causes inhibition of differentiation, maturation and homing of mast cells to allergic airways and down regulation of CD40 and CD80/86 on dendritic cells and regulatory cells along with enhancement of IL-10 and TGF- $\beta$ synthesis [6]. In addition, viral infections were a known primary risk factor in the onset of asthma attack. During a viral infection, vitamin D is responsible for the production of cathelicidinin, an antimicrobial polypeptide. Research exhibits vitamin D supplementation reduce upper respiratory tract infections significantly $[7,8]$. vitamin D regulates inflammatory response by inhibiting the secretion of mediators such as interleukin 2 (IL-2), interferon $\gamma$ (IFN- $\gamma$ ) from $\mathrm{T}$ helper 1 cells and interleukin 4 (IL-4) from T helper 2 cells [9]. Vitamin D deficiency had been related with rising incidence and severity of childhood asthma [10,11]. Certain observational studies found relation between low serum Vitamin D levels and poor asthma control and decreased lung function in children [11-13].

However, other studies had found adverse effects of Vitamin D in asthma [14,15]. Another study had found that Vitamin D supplementation during 1st year of life was related with higher prevalence of allergic rhinitis, atopy and asthma at age of 31 years of life [15]. The question of whether or not Vitamin D deficiency is a risk factor for pediatric asthma needs to be clarified. Thus, this study proposed to see the correlation between serum Vitamin D levels and Asthma severity as well as effect of Vitamin D supplementation on asthma control management.

\section{Material and Methods}

A prospective interventional study was conducted in children $\leq 14$ years old diagnosed as asthma in Department of Pediatrics, S.N. Medical College Agra, from January 2016 to June 2017.

Inclusion criteria: As per GINA guidelines (2015) $\leq 14$ years old children diagnosed as bronchial asthma (either previously on treatment or newly diagnosed) were included in to the study.

Exclusion criteria: 1) History of vitamin D or calcium intake in past 3 months. b) On steroid Written and informed consent were taken from his/her guardian or parents, total 141 cases of childhood asthma who satisfied inclusion and exclusion criteria were recruited for the study. Children were classified into intermittent, mild persistent, moderate persistent and severe persistent asthma according to GINA guideline (2015). Only moderate persistent cases were included in the current study, because other case groups small in number. Study patients were divided in to two groups based on their serum vitamin D level, group A included study subject with normal vitamin D level and group B included subject with subnormal vitamin D level.

Treatment was initiated as per standard treatment protocol by Global Initiative for Asthma 2015. After assessment of serum vitamin D and severity only 119 patients with moderate persistent asthma were recruited for the study. These patients were divided into two groups based on vitamin D level. Asthmatic children with moderate persistent severity and normal vitamin D levels (Group Am) were labeled as control group $(n=31)$ and children with moderate persistent severity and subnormal level of vitamin D level (Group Bm). Children of Group Bm were randomly and equally allocated to two subgroup B1 and B2 (Study group) with 44 cases in each group (Figure 1).

Control group (Group Am) had received standard medication as per GINA guidelines. Study subgroup B1 had received standard medications as per GINA guidelines for 3 month and subgroup B2 had received additional supplementation of vitamin D (STOSS REGIMEN - inj of vitamin D 600,000 IU I/M stat followed by 400 IU /day orally for 6 month ) along with standard medication as per GINA guidelines for 6 month. At the end of 3 month, their asthma control was assessed by using Asthma control test score (A validated questionnaire approved by GINA e.g. Day time symptoms, Night time awakening, Days of absenteeism from school because of asthma), emergency room visits per month, hospital admission 


\section{Original Research Article}

per month and reliever medication use per week. After that, in subgroup B1 vitamin D supplementation was also added along with standard treatment of asthma for another 3 months. Group A and subgroup B2 was on same treatment for another 3 months. Now, their outcomes (asthma control as assessed at 3months) was compared again at the end of 6 months (Figure 1).

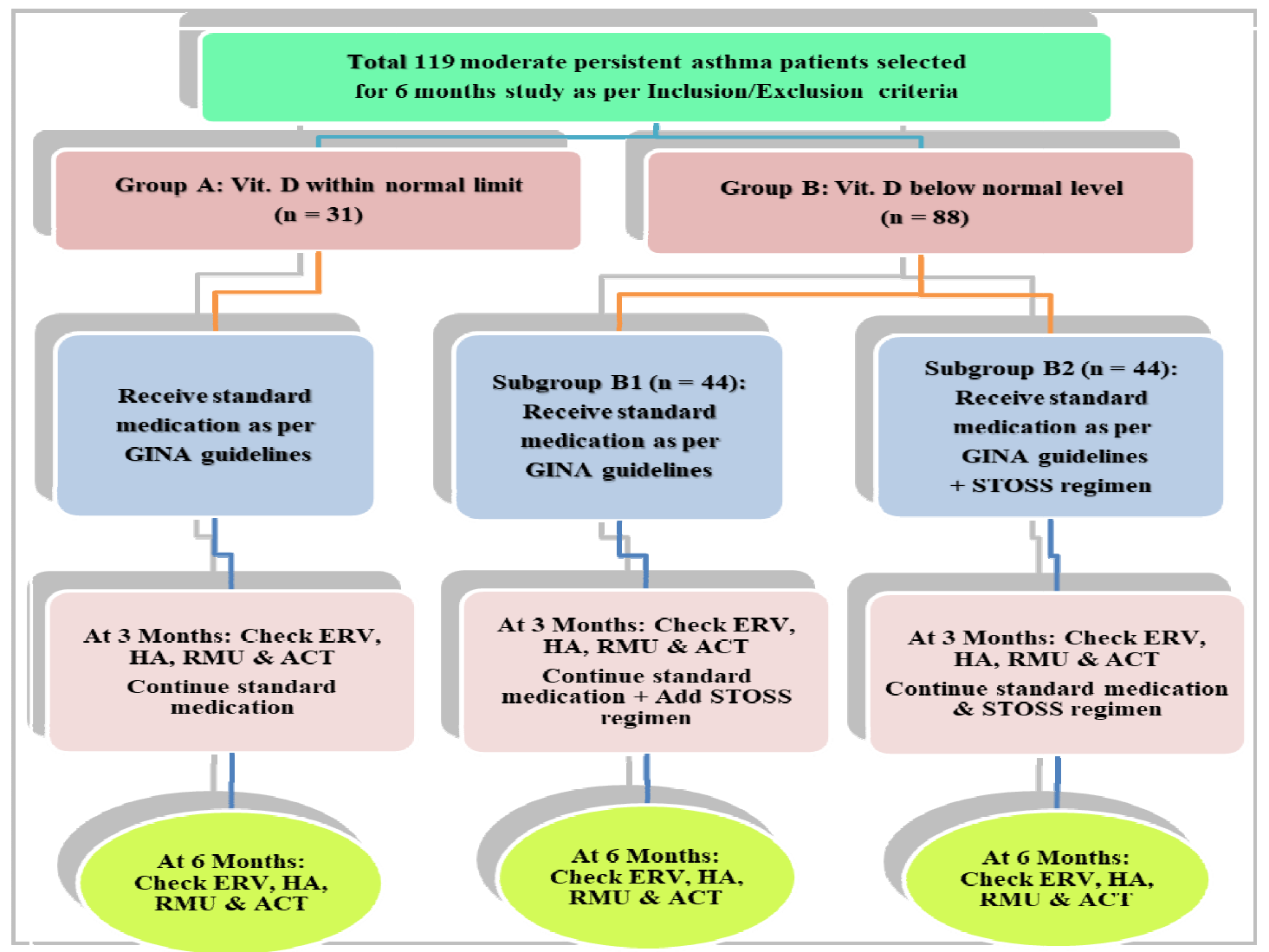

Figure-1: Flow chart of study methodology

At the end of $3 \& 6$ months, outcomes measured in all three groups in the form of ERV (Emergency room visit per month), HA (Hospital admission per month), ACT score (Asthma control test), and RMU (Reliever medication per week). Each patient assessed every month during the course of study. Follow up was done and outcome measure with respect to the following-

$>$ Emergency Room Visits (ERV) per month: 0 (no visit), 1 visit \& $>1$ visits

$>$ Hospital Admission (HA) per month: 0 (no visit), 1 visit \& $>1$ visits

$>$ Reliever Medication Use (RMU) per week: No (not used), 2 times/week $\&>2$ times/week

$>$ Asthma Control test (ACT) score: Well controlled (>20), Partially controlled (16-20), Poor control $(<16)$

Evaluation and statistical analysis: All data entered into MS excel spreadsheets and analyzed using SPSS version 20 into tabular, graphic representation. Statistically test such as t test, one-way ANOVA \& Chi square test applied to check the statistical association.

\section{Results}

At the start of the current study, total 141 cases of childhood asthma were selected and their baseline serum vitamin D level was measured. Majority of patients $(53.9 \%)$ were male with male to female ratio of 1.2:1. Most of the patients belonged to more than 9 but less than/equal to 14 years age (49.7\%), followed by more than 6 but less than/equal to 9 years $(29.1 \%)$, more than 3 but less than/equal to 6 years $(13.5 \%)$ and less than or equal to 3 (7.8\%). Based on severity of asthma, 4 patients $(2.8 \%)$ were suffering from intermittent asthma, 11 patients $(7.8 \%)$ were suffering from mild persistent asthma, 119 patients $(84.4 \%)$ were suffering from moderate persistent asthma and 7 patients (5\%) were suffering from severe persistent asthma. Mean values of serum Vitamin D in asthmatic children were significantly decreasing with the 


\section{Original Research Article}

increasing severity of asthma such as $81.4 \pm 24.1 \mathrm{nmol} / \mathrm{L}$ in intermittent asthma; $53.1 \pm 17.8 \mathrm{nmol} / \mathrm{L}$ in mild persistent asthma; $35.5 \pm 10.5 \mathrm{nmol} / \mathrm{L}$ in moderate persistent asthma and $23.1 \pm 13 \mathrm{nmol} / \mathrm{L}$ in severe persistent asthma. Based on level of serum vitamin D level all patients were distributed into two groups: Group A ( $\mathrm{n}=46$, normal serum vitamin D levels) and Group B ( $\mathrm{n}=95$, subnormal Vitamin D level). Among group A patients, mean value of Serum vitamin D was $72.6 \pm 18.8 \mathrm{nmol} / \mathrm{L}$. While among group B, it was $31.8 \pm 9.1 \mathrm{nmol} / \mathrm{L}$. After assessment of severity and control of asthma in relation to serum vitamin D level, only moderate persistent asthma cases (from both Group A and Group B), were further followed up because other cases very small in number.

Among group Am after starting the standard treatment of asthma, 32.2\% patients did not require emergency room visit at 3 months follow up, This no increased to $38.7 \%$ patients at 6 months follow-up. Hospital admission was not required in $38.7 \%$ patients at 3 months which is increased to $48.4 \%$ at 6 months follow-up. However, $29 \%$ patients did not require reliever medication at 3 months follow-up and this percent raised to $48.4 \%$ at 6 months' follow-up. Though well control asthma (ACT score $\geq 20$ ) was seen in $29 \%$ at 3 months and $38.7 \%$ patients at 6 months (Figures 2-5). Among subgroup B1, vitamin D was added to standard asthma treatment after 3 months follow-up. At 3 months follow-up, 11.4\% patients did not require emergency room visit and this was increased to $25 \%$ patients at 6 months follow-up.

Hospital admission was not required in $15.9 \%$ patients at 3 months which is increased to $43.2 \%$ at 6 months follow-up. However, $18.2 \%$ patients did not require reliever medication at 3 months follow-up and this percent raised to $36.4 \%$ at 6 months' follow-up. Though well control asthma (ACT score $\geq 20$ ) was seen in $18.2 \%$ at 3 months and $25 \%$ patients at 6 months (Figures 2-5).

Among subgroup B2, vitamin D was added to standard asthma treatment at start of study. At 3 months follow-up, 34.1\% patients did not require emergency room visit and this increased to 50\% patients at 6 months follow-up. Hospital admission was also not required in $45.5 \%$ patients at 3 months which is increased to $65.9 \%$ at 6 months follow-up. However, 34.1\% patients did not require reliever medication at 3 months follow-up and this percent increased to $63.6 \%$ at 6 months' follow-up. Though well control asthma (ACT score $\geq 20$ ) was seen in $56.8 \%$ at 3 months and $70.5 \%$ patients at 6 months (Figures 2-5). Mean value of ACT score was also statistically increased in all three groups from 3 months to 6 months follow-up. However, mean values of Asthma control score were higher among subgroup B2 patients at 3 months (19.13 \pm 3.2$)$ and 6 months follow-up (22.2 \pm 2.7$)$ compared to other groups. By applying one way ANOVA test, this difference was found to be statistically significant at 3 months \& 6 months follow up $(\mathrm{P}<0.05)$ (Table 1).

Table-1: Comparison of mean values of ACT score between groups at $3 \& 6$ months and also among groups

\begin{tabular}{|c|c|c|c|c|}
\hline Follow up & $\begin{array}{c}\text { Group A }(\mathbf{n}=\mathbf{3 1}) \\
\text { Mean } \mathbf{+} \text { SD }\end{array}$ & $\begin{array}{c}\text { Group B1 }(\mathbf{n}=\mathbf{4 4}) \\
\text { Mean } \pm \text { SD }\end{array}$ & $\begin{array}{c}\text { Group B2 }(\mathbf{n}=\mathbf{4 4}) \\
\text { Mean } \pm \text { SD }\end{array}$ & $\begin{array}{c}\text { P value (one } \\
\text { way ANOVA) }\end{array}$ \\
\hline 3 Months & $18.75 \pm 2.1$ & $15.85 \pm 2.6$ & $19.13 \pm 3.2$ & $<\mathbf{0 . 0 0 0 1}$ \\
\hline 6 Months & $20.54 \pm 2.8$ & $18.4 \pm 2.6$ & $22.2 \pm 2.7$ & $<\mathbf{0 . 0 0 0 1}$ \\
\hline $\begin{array}{c}\text { Comparisons b/w 3 \& 6 } \\
\text { Months (Paired t test) }\end{array}$ & $\mathbf{0 . 0 0 5 8}$ & $<\mathbf{0 . 0 0 0 1}$ & $<\mathbf{0 . 0 0 0 1}$ & \\
\hline
\end{tabular}

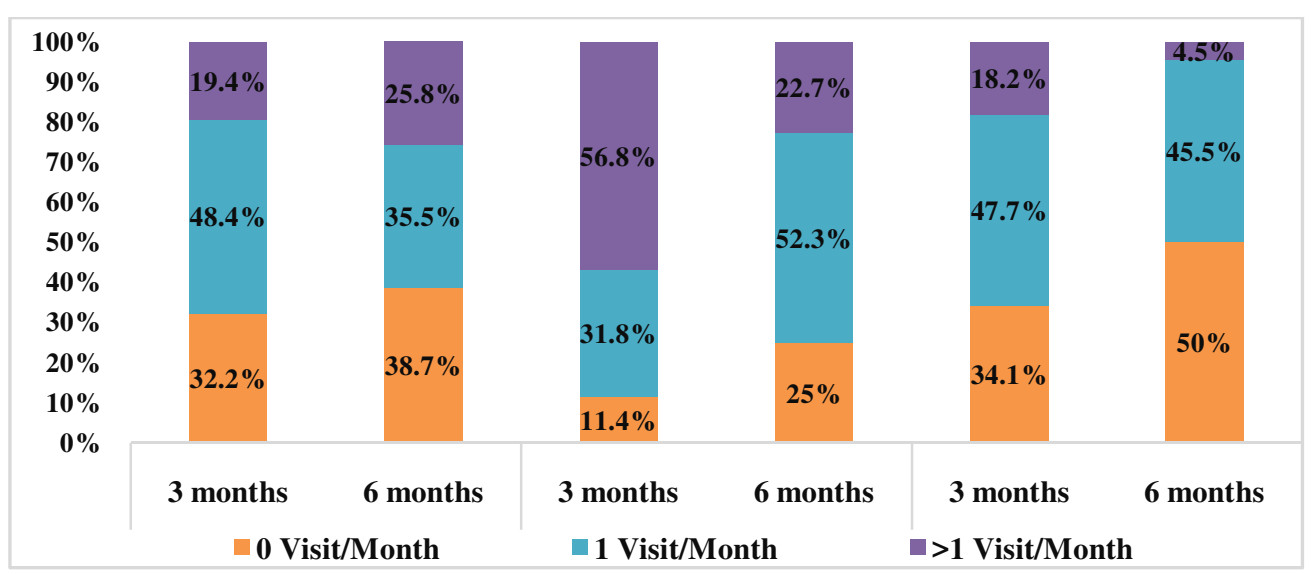

Figure-2: Distribution of patients based on emergency room visit in all three groups at 3 \& 6 Months 


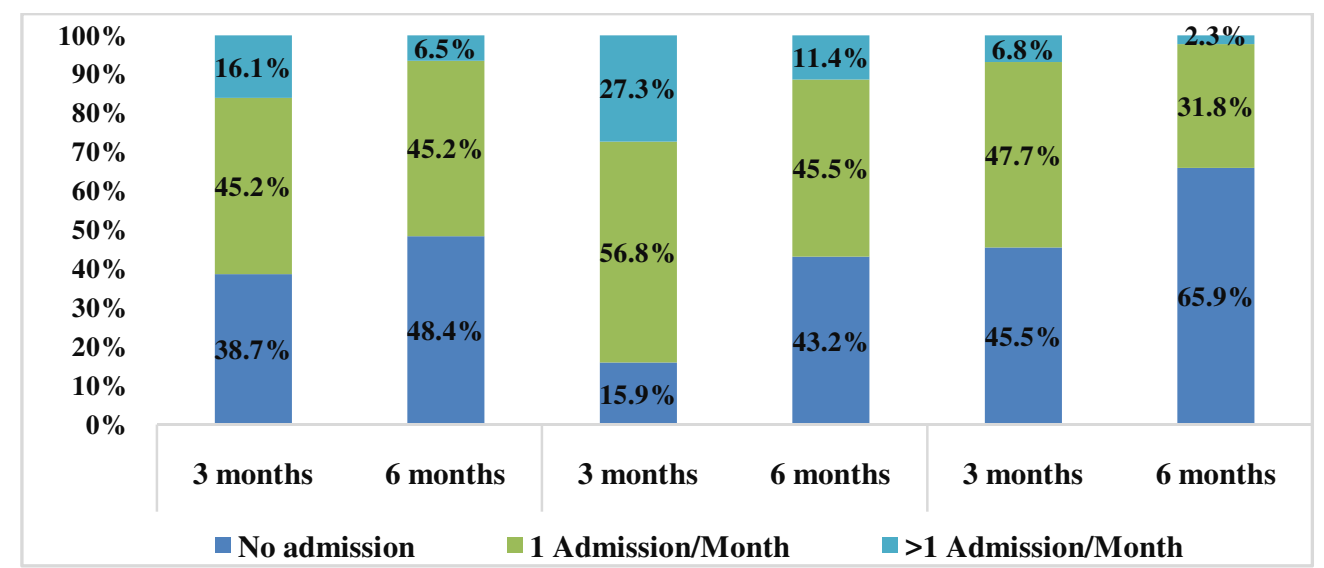

Figure-3: Distribution of patients based on hospital admission in all three groups at 3 \& 6 Months

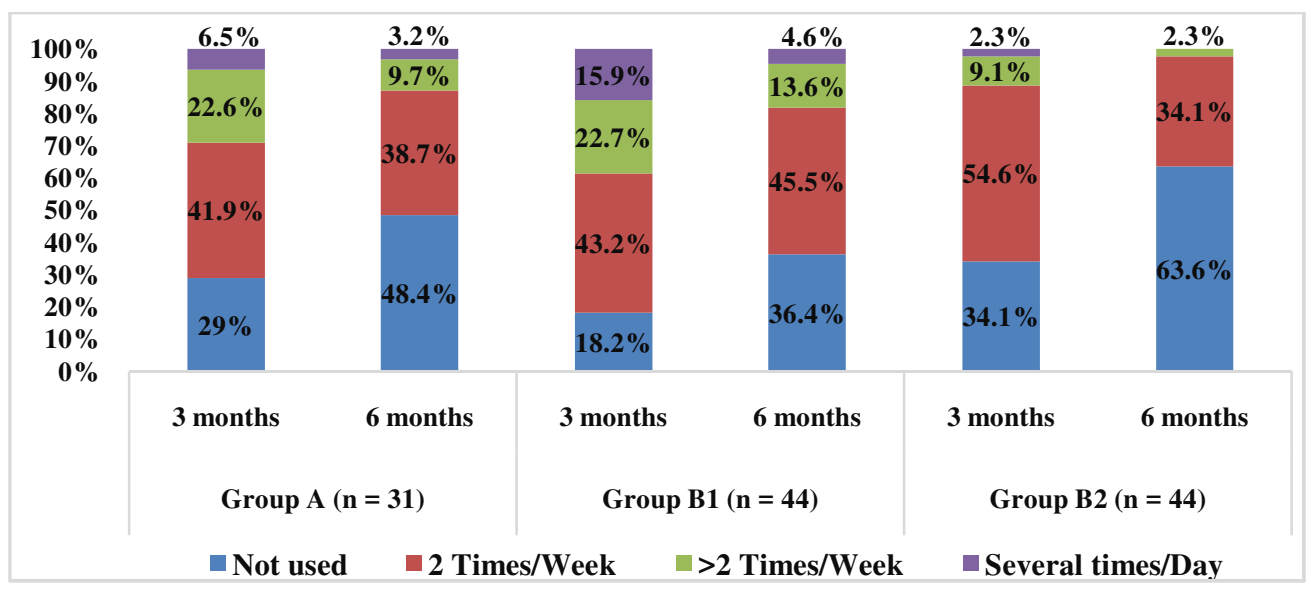

Figure-4: Distribution of patients based on use of Reliever medication in all three groups at 3 \& 6 Months

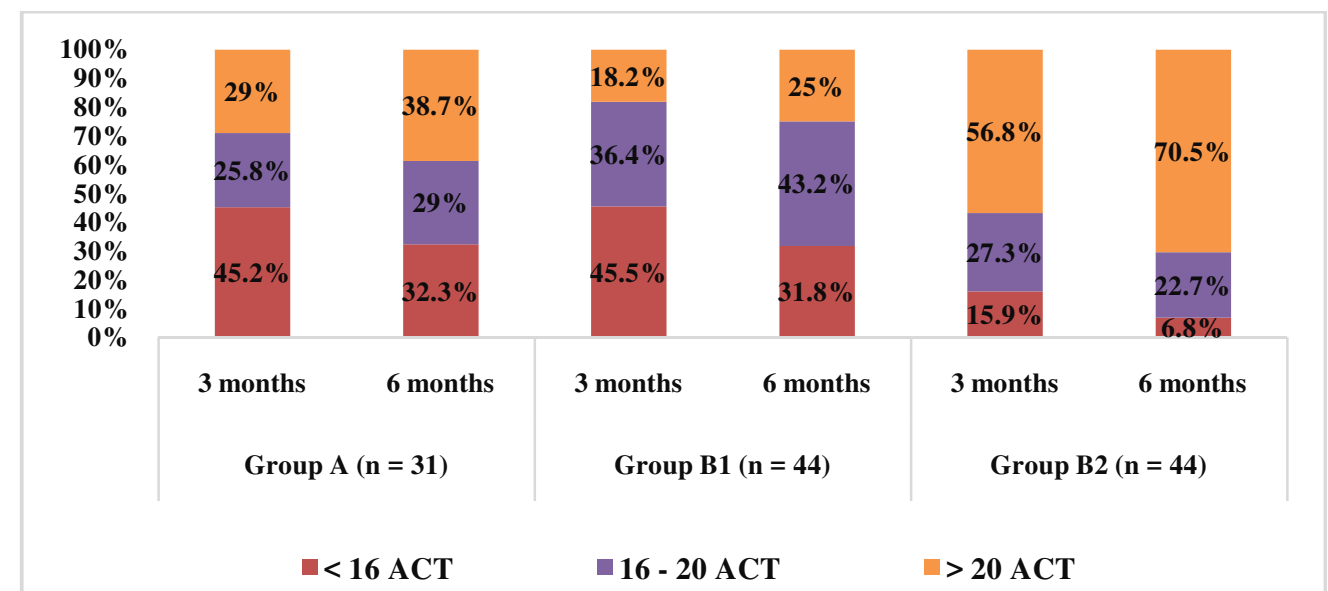

Figure-5: Distribution of patients based on Pediatric ACT score in all three groups at 3 \& 6 Months

\section{Discussion}

Vitamin D produced into human body from 7dehydrocholesterol after exposure to ultraviolet rays of sunlight, though $70-100 \%$ Indian general population had vitamin D in subnormal level. In India, commonly consumed food items such as dairy products were rarely fortify with vitamin $D$. Indian socio-religious and cultural practices limit adequate sun exposure, thus negating probable benefits of plentiful sunshine.
Therefore, subclinical vitamin D deficiency was highly prevalent in both urban and rural settings, and across all socioeconomic and geographic strata [16]. According to a Cochrane review, addition of vitamin D supplements to standard asthma medication could lead to fewer asthma exacerbation in patients with mild to moderate asthma [17]. In current study, male patients (53.9\%) were in majority with male to female ratio of 1.2:1. 


\section{Original Research Article}

Similarly male dominancy seen in a study by Krishnan et al[18] (59.4\%). Most of the patients were belongs to 9 - 14 years age (49.7\%), similarly Chhabra et al [19] found highest prevalence of asthma in 9-13 years age group. However, Krishnan et al[18] found commonest age group was $5-8$ years $(57.3 \%)$. In current study, $84.4 \%$ patients had moderate persistent asthma, 7.8\% had mild persistent asthma, 5\% severe persistent asthma and $2.8 \%$ had intermittent asthma. However, in a study by Krishnan et al[18] had found majority of children had mild persistent asthma (55.2\%) followed by moderate persistent $(24 \%)$, intermittent $(12.5 \%)$ and severe persistent $(8.3 \%)$.

Present study found that $67.4 \%$ patients had subnormal level of serum vitamin D and $32.6 \%$ cases had normal levels of it. Similarly, Uysalol et al[20] recorded that $90.6 \%$ asthmatic patient had serum vitamin D deficiency as compared to $67.7 \%$ in control group. Current study had found significantly decreasing levels of mean serum vitamin D in asthmatic children with the increasing severity of asthma.

Similarly, El-naggar et al [21] and Elnady et al [22] had found significantly decreasing levels of serum vitamin D with increasing severity of asthma. Other studies conducted by Krishnan et al [18], Majak et al [23] and Gupta A et al [24] had statistically significant relation of level of vitamin D with severity of asthma.

Present study had found that there was more reduction in emergency hospital visit and hospital admission after addition of vitamin D to standard asthma treatment at start of study among group B2 as compared to group A (normal Vitamin-D) and group B1 (subnormal VitaminD). Present study also found that requirement of reliever medication was very less among subgroup B2 as compared to other two groups. These things lead to better control of asthma among subgroup B2 compared to other two groups (Figures 2-5).

These findings supported by the study conducted by Krishnan et al [18] who found significant correlation of asthma control and vitamin D levels $(\mathrm{p}<0.001)$, marked reduction in emergency room visits, hospital admission and reliever medication usage over a period of 6 months. Gupta A et al 24] also found children with normal vitamin D level had few exacerbation (pvalue $<0.001)$ and better asthma control $(\mathrm{p}<0.001)$.

Berhm et al [11] found that asthmatic children with lower vitamin D had higher rate of hospitalization and emergency room visits $(p=0.01)$. Reduction in asthma attack after vitamin D supplementation was also found by Urashima et al[25]. Majak et al [23] had found that asthma exacerbation were significantly lower in study group $(n=24)$ compared to control group $(n=24)$ evidenced by $(\mathrm{p}=0.029)$.

Current study had found that mean value of ACT score was statistically increased in all three groups from 3 months to 6 months follow-ups. However, mean values of asthma control score was significantly higher among subgroup B2 patients at 3 months $(19.13 \pm 3.2)$ and 6 months follow-up $(22.2 \pm 2.7)$ compared to other groups (Table1). Krishnan et al[18] had recorded significant difference in asthma control test score at 3rd and 6th $\operatorname{month}(\mathrm{p}=0.008)$.

\section{Conclusion}

The present study suggests that vitamin D deficiency is commonly seen in asthmatic patients. There is a significant inverse correlation between vitamin D level, asthma severity and its control. Asthma exacerbation in terms of emergency room visits and reliever medication was use further reduced by vitamin D supplementation.

This may be because of potentiating effect of vitamin D on glucocorticoids. Measurement of serum levels of vitamin D and supplementation in case of subnormal levels might be considered in patients with bronchial asthma especially un-controlled or severe asthmatic patients.

Contributors: Dr. Dayal provided idea of topics, supervised ongoing study, guidance in analysis and drafting the manuscript. Dr Aneeta collected data of study, made analysis and prepared the initial draft of the paper. He would act as guarantor for the paper. Other authors also helped in the analysis, finalizing of the manuscript and provided support, encouragement to carry out this study.

Funding: Nil, Conflict of interest: None initiated, Perission from IRB: Yes

\section{References}

1. Wang LY, Zhong Y, Wheeler L. PEER REVIEWED: Direct and Indirect Costs of Asthma in School-age Children. Prev Chronic Dis. 2005;2(1).

2. GINA. Global Initative for Asthma [Internet]. 2018. Available from: www.ginasthma.org

3. WHO. Bronchial Asthma [Internet]. 2018 [cited 2018 Apr 25]. Available from: http://www.who.int / mediacentre / factsheets/fs206/en/ 


\section{Original Research Article}

4. El-Menem MTA, Al-Aziz MMA, El-Guindy WM, El Banna NA. The frequency of vitamin D deficiency among asthmatic Egyptian children. Egypt J Pediatr Allergy Immunol. 2013;11(2):69-74.

5. Krobtrakulchai W, Praikanahok J, Visitsunthorn N, Vichyanond P, Manonukul K, Pratumvinit B, et al. The effect of vitamin D status on pediatric asthma at a university hospital, Thailand. Allergy Asthma Immunol Res. 2013;5(5):289-94.

6. Bateman ED, Boushey HA, Bousquet J, Busse WW, Clark TJH, Pauwels RA, et al. Can guideline-defined asthma control be achieved? The Gaining Optimal Asthma ControL study. Am J Respir Crit Care Med. 2004;170(8):836-44.

7. Asilsoy S. Vitamin D and allergic diseases. Asthma Allergy Immunol. 2011;9(1):1-7.

8. Xystrakis E, Kusumakar S, Boswell S, Peek E, Urry $\mathrm{Z}$, Richards DF, et al. Reversing the defective induction of IL-10-secreting regulatory $\mathrm{T}$ cells in glucocorticoidresistant asthma patients. J Clin Invest. 2006; 116 (1): $146-55$.

9. Della Giustina A, Landi M, Bellini F, Bosoni M, Ferrante G, Onorari M, et al. Vitamin D, allergies and asthma: focus on pediatric patients. World Allergy Organ J. 2014;7(1):1.

10. Van Oeffelen AAM, Bekkers MBM, Smit HA, Kerkhof M, Koppelman GH, Haveman-Nies A, et al. Serum micronutrient concentrations and childhood asthma: the PIAMA birth cohort study. Pediatr Allergy Immunol. 2011;22(8):784-93.

11. Brehm JM, Celedón JC, Soto-Quiros ME, Avila L, Hunninghake GM, Forno E, et al. Serum vitamin D levels and markers of severity of childhood asthma in Costa Rica. Am J Respir Crit Care Med. 2009;179 (9): 765-71.

12. Chinellato I, Piazza M, Sandri M, Peroni DG, Cardinale F, Piacentini GL, et al. Serum vitamin D levels and exercise-induced bronchoconstriction in children with asthma. Eur Respir J. 2011;37(6): 1366-70.

13. Brehm JM, Schuemann B, Fuhlbrigge AL, Hollis BW, Strunk RC, Zeiger RS, et al. Serum vitamin D levels and severe asthma exacerbations in the Childhood Asthma Management Program study. J Allergy Clin Immunol. 2010;126(1):52-8.
14. Gale CR, Robinson SM, Harvey NC, Javaid MK, Jiang B, Martyn CN, et al. Maternal vitamin D status during pregnancy and child outcomes. Eur J Clin Nutr. 2008;62(1):68.

15. HYPPöNEN E, Sovio U, Wjst M, Patel S, Pekkanen J, HARTIKAINEN A, et al. Infant vitamin D supplementation and allergic conditions in adulthood: northern Finland birth cohort 1966. Ann N Y Acad Sci. 2004;1037(1):84-95.

16. G R, Gupta A. Vitamin D Deficiency in India: Prevalence, Causalities and Interventions. Nutrients [Internet]. 2014 Feb 21; 6(2):729-75. Available from: http:// www. ncbi. nlm.nih. gov/ pmc/ articles/ PMC 3942730/

17. Kate Johnson. Vitamin D Eases Asthma, Cochrane Review Finds [Internet]. Medscape. 2016 [cited 2018 Apr 25]. p.1-2. Available from:https://www. medscape. com/viewarticle/868575

18. Krishnan E, Ponnusamy V, Sekar SP. Trial of vitamin D supplementation to prevent asthma exacerbation in children. 2017;5(6):2734-40.

19. Chhabra SK, Gupta CK, Chhabra P, Pal SR. Prevalence of bronchial asthma in schoolchildren in Delhi. J asthma. 1998;35(3):291-6.

20. Uysalol M, Mutlu LC, Saracoglu GV, Karasu E, Guzel S, Kayaoglu S, et al. Childhood asthma and vitamin D deficiency in Turkey: is there cause and effect relationship between them? Ital J Pediatr. 2013; 39 (1):78.

21. El-Naggar EM, Handoka NM, Younes SE, ElRahman AAA. Detection of Vitamin (D) deficiency in children and adolescents suffering from bronchial asthma in Suez Canal University Hospital, Ismailia. Egypt J Pediatr Allergy Immunol. 2015; 13 (2): $73-7$.

22. Elnadya HG, Foudac EM, Elsheikha OM, ElAlameeya IR, Elshafied AI, Sherifa LS, et al. Serum vitamin D level as a predictor of bronchial asthma in Egyptian Children. J Arab Soc Med Res. 2013; $8(2): 67$.

23. Majak P, Olszowiec-Chlebna M, Smejda K, Stelmach I. Vitamin D supplementation in children may prevent asthma exacerbation triggered by acute respiratory infection. J Allergy Clin Immunol. 2011; 127 (5):1294-6. 


\section{Original Research Article}

24. Gupta A, Sjoukes A, Richards D, Banya W, Hawrylowicz C, Bush A, et al. Relationship between serum vitamin D, disease severity, and airway remodeling in children with asthma. Am J Respir Crit Care Med. 2011;184(12):1342-9.
25. Urashima M, Segawa T, Okazaki M, Kurihara M, Wada Y, Ida H. Randomized trial of vitamin D supplementation to prevent seasonal influenza $A$ in schoolchildren-. Am J Clin Nutr. 2010;91(5):1255-60.

\section{How to cite this article?}

Agrahari A, Dayal R, Gupta L.K, Bhatia R, Agarwal D, Kumar P, Pathak S, Kumar H. Effect of vitamin D supplementation in severity and control of bronchial asthma in children. Int J Pediatr Res. 2019;6(02):50-57. doi:10.17511/ijpr.2019.i02.01 